\title{
Proteomic Studies in Plants
}

\author{
Ohkmae K. Park* \\ Kumho Life and Environmental Science Laboratory, Gwangju 500-712, Korea
}

Received 11 December 2003

\begin{abstract}
Proteomics is a leading technology for the high-throughput analysis of proteins on a genome-wide scale. With the completion of genome sequencing projects and the development of analytical methods for protein characterization, proteomics has become a major field of functional genomics. The initial objective of proteomics was the large-scale identification of all protein species in a cell or tissue. The applications are currently being extended to analyze various functional aspects of proteins such as posttranslational modifications, protein-protein interactions, activities and structures. Whereas the proteomics research is quite advanced in animals and yeast as well as Escherichia coli, plant proteomics is only at the initial phase. Major studies of plant proteomics have been reported on subcellular proteomes and protein complexes (e.g. proteins in the plasma membranes, chloroplasts, mitochondria and nuclei). Here several plant proteomics studies will be presented, followed by a recent work using multidimensional protein identification technology (MudPIT).
\end{abstract}

Keywords: Functional genomics, Mass spectrometry, Proteomics, Plant, Two-dimensional gel electrophoresis

\section{Introduction}

Proteomics can be defined as the systematic analysis of proteome, the protein complement of genome (Pandey and Mann, 2000; Patterson and Aebersold, 2003; Phizicky et al., 2003). This technology allows the global analysis of gene products in various tissues and physiological states of cells. With the completion of genome sequencing projects and the development of analytical methods for protein characterization, proteomics has become a major field of functional genomics. The initial objective of proteomics was the large-scale identification of all protein species in a cell or

*To whom correspondence should be addressed.

Tel: 82-62-970-2625; Fax: 82-62-972-5085

E-mail: omkim@kkpc.com tissue. The applications are currently diversified to analyze various functional aspects of proteins such as posttranslational modifications, protein-protein interactions, activities and structures. Here, general technologies of proteomics will be briefly introduced, followed by the overall progress in plant proteomics.

With the aim of profiling proteins in biological samples, proteomics has long been associated with the techniques of two-dimensional gel electrophoresis (2DE) and mass spectrometry (MS) (Shevchenko et al., 1996; Wilkins et al., 1996). Classical 2DE had limitations in resolution and reproducibility of gels, which were mostly overcome by using immobilized $\mathrm{pH}$ gradient (IPG) strips (Gorg, 1991). The improved techniques in 2DE allowed comprehensive protein visualization on 2D gels. Proteomics was further advanced by the development of biological MS and the growth of searchable sequence databases. The MS techniques that were developed for the ionization of proteins and peptides include matrix-associated laser desorption ionization (MALDI) and electrospray ionization (ESI) (Karas and Hillenkamp, 1988; Fenn et al., 1989). Combined with time of flight (TOF), ion trap and triple-quadrupole tandem MS (MS/MS) spectrometers, these offer high sensitivity and mass accuracy (Aebersold and Mann, 2003).

Although 2DE-based proteomics has proven powerful for the global analysis of proteins, it still retains technical problems that need to be solved (Corthals et al., 2000; Gygi et al., 2000). It is costly and a labor- and time-consuming process, limiting high-throughput analysis of protein expression. In addition, the entire protein profiling and quantification are not possible due to the limited loading capacity and incomplete staining methods. An alternative method to analyze proteins directly by MS, without gel separation, has been developed to overcome these 2DEassociated limitations. It is referred to as multidimensional protein identification technology (MudPIT) or liquid chromatography (LC)-MS/MS that couples capillary, highperformance liquid chromatography (HPLC) to MS/MS and allows automated analyses of peptide mixtures that are generated from complex protein samples (Appella et al., 1995; Washburn et al., 2001; Wolters et al., 2001). 
Furthermore, quantitative proteomics became feasible using an innovative reagent, termed isotope-coded affinity tag (ICAT), in the LC-MS/MS system (Han et al., 2001).

Several intriguing strategies have been developed toward large-scale studies of protein functions. Following the successful applications of DNA chip methods, protein microarray technology has emerged (Macbeath, 2002; Mitchell, 2002). The complicated features of protein microarray are that proteins have different biochemical properties and need high-throughput methods for expression and purification. There are some reports of comprehensive protein microarray screening (Houseman and Mrksich, 2002; Schweitzer et al., 2002). In addition, studies of protein-protein interactions lead into cellular protein functions. There have been large-scale analyses of protein complexes in yeast, using the tandem-affinity purification (TAP) approach combined with MS (Gavin et al., 2002; Ho et al., 2002). Researchers isolated and identified more than 200 protein complexes, providing clues how an entire proteome is organized into functional units.

While proteomics research is advanced in animals and yeast, plant proteomics is still at the initial phase (Zivy and de Vienne, 2000; van Wijk, 2001; Kersten et al., 2002). The progress in plant proteomics has been largely made by $2 \mathrm{DE}-$ based proteomic approaches. Since the resolution of protein spots on a 2D gel is limited by factors such as abundance, size, and other electrophoretic properties, the complete proteome has been fractionated into sub-proteomes such as subcellular compartments, organelles and multiprotein complexes to improve sensitivity and resolution and to reduce the overall complexity (Jung et al., 2000). Several proteomics groups have studied subcellular proteomes and protein complexes in plants, e.g. proteins in the plasma membranes, chloroplasts, mitochondria and nuclei (Rouquie et al., 1997; Peltier et al., 2000; Prime et al., 2000; Peltier et al., 2001; Kruft et al., 2001; Millar et al., 2001; Bae et al., 2003). In a recent paper, MudPIT was used to analyze rice proteome, in which the combined 2DE and MudPIT approaches identified 2,528 unique proteins (Koller et al., 2002; Whitelegge, 2002). In this article, several plant proteomics studies will be presented that focused on subcellular proteomes and protein complexes (Table 1). A recent work using MudPIT will also be briefly described.

\section{Chloroplast Proteome}

It is estimated that the chloroplast contains 2,500 to 5,000

Table 1. Proteomic studies in different subcellular compartments in plants

\begin{tabular}{|c|c|c|}
\hline Subcellular compartments & Summary of studies & References \\
\hline Chloroplast & $\begin{array}{l}61 \text { lumenal and peripheral thylakoid proteins in pea identified by } \\
\text { MALDI-TOF MS, ESI MS/MS and Edman sequencing; } \\
\text { more than } 100 \text { envelope membrane proteins in Arabidopsis identified by } \\
\text { LC-MS/MS; } \\
\text { 350-kDa ClpP protease complex with } 10 \text { different isoforms in Arabidopsis } \\
\text { identified by blue-native gel electrophoresis, MALDI-TOF MS and ESI } \\
\text { MS/MS; } \\
\text { light-harvesting proteins of photosystems I \& II in } 14 \text { and } 9 \text { different plant } \\
\text { species, respectively, identified by reverse phase HPLC-ESI-MS }\end{array}$ & $\begin{array}{l}\text { Peltier et al., } 2000 \\
\text { Ferro et al., } 2003 \\
\text { Peltier } \text { et al., } 2001 \\
\text { Zolla et al., 2002, } 2003\end{array}$ \\
\hline Mitochondria & $\begin{array}{l}52 \text { mitochondrial proteins in Arabidopsis identified by immunoblotting, } \\
\text { Edman sequencing, MALDI-TOF MS and ESI MS/MS; } \\
91 \text { mitochondrial proteins in Arabidopsis identified by MALDI-TOF MS; } \\
\text { protein complexes, ATP synthase complex, cytochrome } c \text { reductase complex } \\
\text { and TOM complex, in Arabidopsis resolved by 3DE; } \\
\text { subunits of TOM complex in Arabidopsis identified by immunoblotting and } \\
\text { direct sequencing }\end{array}$ & $\begin{array}{l}\text { Kruft et al., } 2001 \\
\text { Millar et al., } 2001 \\
\text { Werhahn and Braun, } \\
2002 \\
\text { Werhahn } \text { et al., } 2001\end{array}$ \\
\hline Nucleus & 184 nuclear proteins in Arabidopsis identified by MALDI-TOF MS & Bae et al., 2003 \\
\hline Plasma membrane & $\begin{array}{l}82 \text { proteins in plasma membrane and soluble fractions in Arabidopsis } \\
\text { identified by direct sequencing; } \\
38 \text { plasma membrane proteins associated with cold acclimation in } \\
\text { Arabidopsis identified by MALDI-TOF MS }\end{array}$ & $\begin{array}{l}\text { Santoni et al., } 1998 \\
\text { Kawamura and } \\
\text { Uemura, } 2003\end{array}$ \\
\hline Cell wall & $\begin{array}{l}111 \text { cell wall proteins in Arabidopsis identified by MALDI-TOF MS; } \\
\text { extracellular proteins responding to fungal elicitors in Arabidopsis } \\
\text { suspension cultures identified by immunoblotting and MALDI-TOF MS }\end{array}$ & $\begin{array}{l}\text { Chivasa et al., } 2002 \\
\text { Ndimba et al., } 2003\end{array}$ \\
\hline $\begin{array}{l}\text { Post-translational } \\
\text { modification }\end{array}$ & $\begin{array}{l}\text { thylakoid proteins reversibly phosphorylated in Arabidopsis identified by } \\
\text { MALDI-TOF MS and ESI MS/MS; } \\
\text { 30 GAPs identified by LC-MS/MS and } 248 \text { GAPs predicted by a } \\
\text { bioinformatic analysis in Arabidopsis }\end{array}$ & $\begin{array}{l}\text { Vener et al., } 2001 \\
\text { Borner et al., } 2003\end{array}$ \\
\hline
\end{tabular}


proteins. Since the chloroplast genome encodes approximately 120 proteins, most proteins are encoded by the nuclear genome and transported into the chloroplast (Keegstra and Cline, 1999). To have a complete picture of the chloroplast proteome, further fractionation into smaller sub-proteomes is required.

The soluble and peripheral proteins in the thylakoids of pea were systematically analyzed by using $2 \mathrm{DE}, \mathrm{MS}$ and $\mathrm{N}$ terminal Edman sequencing, followed by database searching (Peltier et al., 2000). Among the estimated 200 to 230 lumenal and peripheral proteins, 61 proteins were identified. For 18 of those, no corresponding full-length genes could be found in the databases. The predictions for chloroplast localization and transit peptides were made with three on-line programs, ChloroP, PSORT and SignalP, showing that a combination of these three programs provide a useful tool for evaluating localization and targeting.

The chloroplast envelope membranes from Arabidopsis were subjected to an extensive proteomic analysis (Ferro et al., 2003). Purification and extraction methods were developed to prepare highly-purified envelope membranes and as many proteins as possible. LC-MS/MS analyses were then performed, leading to the identification of more than 100 proteins. Regarding functions, approximately $50 \%$ of the identified proteins have functions known, or very likely to be associated, with the chloroplast envelope. Proteins implicated in proteolysis, carbon metabolism and oxidative stress response were also found.

A $350-\mathrm{kDa} \mathrm{ClpP}$ protease complex with 10 different subunits was identified in the chloroplasts of Arabidopsis, using blue-native gel electrophoresis, followed by MALDITOF MS and nano-ESI MS/MS (Peltier et al., 2001). It includes pClpP, 5 nuclear-encoded ClpP proteins, 3 nuclearencoded ClpR proteins, as well as 1 novel Clp protein, ClpS1. Several truncations and errors in intron and exon prediction of the annotated Clp genes were corrected using MS data and by matching genomic sequences with cDNA sequences.

The light-harvesting proteins of photosystems I \& II from different plant species were extracted and identified on the basis of their intact molecular masses by reversed phase HPLC-ESI-MS (Zolla et al., 2002, 2003). During the last several years, reversed phase HPLC-ESI-MS has evolved into a highly powerful tool for accurate mass measurements of proteins (Premstaller et al., 2001) and has been applied to the analysis of plant proteins (Whitelegge et al., 1998; Huber et al., 2001; Gómez et al., 2002).

\section{Mitochondrial Proteome}

The Arabidopsis mitochondrial proteome was systematically analyzed (Kruft et al., 2001; Millar et al., 2001). Using different conditions that were combined for protein solubilization and isoelectric focusing, up to 800 proteins were resolved on 2D gels. About 100 different mitochondrial proteins were identified by MS, direct protein sequencing or immunoblotting analyses. The identified proteins participate in various processes, such as respiration, citric acid cycle, amino acid and nucleotide metabolism, protein import, processing, assembly, transcription, membrane transport and antioxidant defense. More than $20 \%$ of the identified proteins were not previously described for plant mitochondria, indicating novel mitochondrial functions.

The Arabidopsis mitochondrial proteome was further subdivided into sub-proteomes on the basis of protein complexes (Werhahn and Braun, 2002). The mitochondrial protein complexes that are separated by blue-native gel electrophoresis were electroeluted and analyzed by $2 \mathrm{DE}$. This method allowed the resolution of the ATP synthase complex, the cytochrome $c$ reductase complex and the preprotein translocase of the outer mitochondrial membrane (TOM complex). The TOM complex from Arabidopsis was purified and characterized (Werhahn et al., 2001). On blue-native gels, the TOM complex run at $230 \mathrm{kDa}$ and could be dissected into different subunits. A 2DE analysis led to the identification of multiple forms of TOM20.

\section{Nuclear Proteome}

The Arabidopsis nuclear proteome was comprehensively characterized (Bae et al., 2003). Nuclear proteins were isolated and analyzed using 2DE and MALDI-TOF MS. Proteomic analyses led to the identification of proteins that are implicated in a variety of cellular functions such as signaling, gene regulation, structure, translation, proteolysis and various RNA-associated functions. Furthermore, the changes in the nuclear proteome were analyzed in response to cold stress. Of the identified 184 proteins, 54 were up- or downregulated in response to cold treatment.

\section{Plasma Membrane Proteome}

The proteome of the plasma membrane is a difficult one for reproducible and complete mapping due to its hydrophobic nature. Specific strategies have been developed to recover the hydrophobic membrane proteins on 2D gels (Santoni et al., 2000). Efforts have been employed to construct $2 \mathrm{DE}$ reference maps of the plasma membrane under optimized solubilizing conditions (Rouquie et al., 1997; Santoni et al., 1998).

In order to identify Arabidopsis plasma membrane proteins that are associated with the early stage of cold acclimation, highly-purified plasma membrane fractions from nonacclimated and cold-acclimated Arabidopsis leaves were analyzed using MALDI-TOF MS (Kawamura and Uemura, 2003). The proteins that changed in quantity during cold acclimation included those that are associated with membrane repair by membrane fusion, protection of the membrane against osmotic stress, enhancement of $\mathrm{CO}_{2}$ fixation and proteolysis. 


\section{Secreted Proteome}

Proteins were sequentially extracted from enriched Arabidopsis cell wall fractions using $\mathrm{CaCl}_{2}$ and a urea buffer, separated by 2DE, and identified by MALDI-TOF MS and genomic database searches (Chivasa et al., 2002). Among the identified proteins were classical cell wall proteins of known functions. The results also demonstrated the unusual cell wall localization of proteins that are normally associated with other organelles and the existence of extracellular phosphorylation in plants. In addition, Arabidopsis cell suspension cultures were investigated for the proteomic changes that are induced by fungal elicitors (Ndimba et al., 2003). There were extracellular proteins that changed in abundance or in phosphorylation following elicitation.

\section{Post-translational Modifications}

Proteins undergo post-translational modifications such as phosphorylation, glycosylation, sulfation, prenylation, acetylation and ubiquitination. Post-translational modifications modulate protein functions including activity, stability and localization. Proteomic strategies have been developed to characterize protein modifications that cannot be predicted from a genomic sequence (Mann and Jensen, 2003).

The reversible phosphorylation of chloroplast thylakoid proteins in Arabidopsis was analyzed using MALDI-TOF MS and ESI MS/MS (Vener et al., 2001). By comparing the levels of phospho- and nonphosphopeptides, the in vivo phosphorylation states of these proteins were determined under different physiological conditions.

The combination of 2DE and 1DE with Triton X-114 phase partitioning showed that glycosylphosphatidylinositol (GPI)anchored proteins (GAPs) are an abundant class of proteins in plants. They are present at the plasma membrane and also released into the extracellular matrix (Boner et al., 2003). Using LC-MS/MS, 30 GAPs were identified. Furthermore, a bioinformatic analysis was performed using the improved search algorithm, which raised the total to 248 predicted GAPs in Arabidopsis (Borner et al., 2002, 2003).

\section{Rice Proteomics}

Rice is the first cereal crop genome to be decoded. The rice proteome has been systematically analyzed using 2DE, Nterminal sequencing and MS methods (Komatsu et al., 2003; Rakwal and Agrawal, 2003).

Recently, a systematic proteomic analysis of rice leaf, root and seed tissue using two independent technologies, 2DE followed by LC-MS/MS and MudPIT, allowed the detection and identification of 2,528 unique proteins (Koller et al., 2002). Among them, 189 proteins (corresponding to 7.5\%) that were detected in all of the tissues were found to be involved in the central metabolic pathways, transcription control and mRNA biosynthesis, and protein biosynthesis. The majority of proteins showed a tissues-specific expression pattern. The expression patterns of proteins, which were identified and classified as being involved in metabolic pathways were visualized on a metabolic map to illustrate the contribution of proteins to tissue-specific metabolic pathways.

\section{Conclusions}

In the post-genomic era, proteomics is positioned at the center of the functional genomics to study gene function on a genome-wide scale. The unique feature of proteomics is its feasibility to analyze the changes occurring at the protein level that cannot be predicted from genomic sequence. Proteins undergo post-translational modifications, proteolysis, recycling, multicomplex formation and subcellular translocation that are key events to regulate protein functions in cellular processes. Proteomics can eventually reveal all proteins in a cell or tissue at any given time, including those with post-translational changes. However, it also has technical limitations that are continually being researched. With the improved strategies, proteomics will surely provide powerful tools to disclose gene function in plant biology.

\section{References}

Aebersold, R. and Mann, M. (2003) Mass spectrometry-based proteomics. Nature 422, 198-207.

Appella, E., Padlan, E. A. and Hunt, D. F. (1995) Analysis of the structure of naturally processed peptides bound by class I and class II major histocompatibility complex molecules. EXS 73, 105-119.

Bae, M. S., Cho, E. J., Choi, E.-Y. and Park, O. K. (2003) Analysis of the Arabidopsis nuclear proteome and its response to cold stress. Plant J. 36, 652-663.

Borner, G. H., Lilley, K. S., Stevens, T. J. and Dupree, P. (2003) Identification of glycosylphosphatidylinositol-anchored proteins in Arabidopsis. A proteomic and genomic analysis. Plant Physiol. 132, 568-577.

Borner, G. H., Sherrier, D. J., Stevens, T. J., Arkin, I. T. and Dupree, P. (2002) Prediction of glycosylphosphatidylinositolanchored proteins in Arabidopsis. A genomic analysis. Plant Physiol. 129, 486-499.

Chivasa, S., Ndimba, B. K., Simon, W. J., Robertson, D., Yu, X. L., Knox, J. P., Bolwell, P. and Slabas, A. R. (2002) Proteomic analysis of the Arabidopsis thaliana cell wall. Electrophoresis 23, 1754-1765.

Corthals, G. L., Wasinger, V. C., Hochstrasser, D. F. and Sanchez, J. C. (2000) The dynamic range of protein expression: a challenge for proteomic research. Electrophoresis 21, 11041115.

Fenn, J. B., Mann, M., Meng, C. K., Wong, S. F. and Whitehouse, C. M. (1989) Electrospray ionization for mass spectrometry of large biomolecules. Science 246, 64-71. 
Ferro, M., Salvi, D., Brugiere, S., Miras, S., Kowalski, S., Louwagie, M., Garin, J., Joyard, J. and Rolland, N. (2003) Proteomics of the chloroplast envelope membranes from Arabidopsis thaliana. Mol. Cell Proteomics 2, 325-345.

Gavin, A. C., Bosche, M., Krause, R., Grandi, P., Marzioch, M., Bauer, A., Schultz, J., Rick, J. M., Michon, A. M., Cruciat, C. M. et al. (2002) Functional organization of the yeast proteome by systematic analysis of protein complexes. Nature 415, 141147.

Gómez, S. M., Nishio, J. N., Faull, K. F. and Whitelegge, J. P. (2002) The chloroplast grana proteome defined by intact mass measurements from liquid chromatography mass spectrometry. Mol. Cell Proteomics 1, 46-59.

Gorg, A. (1991) Two-dimensional electrophoresis. Nature 349, 545-546.

Gygi, S. P., Corthals, G. L., Zhang, Y., Rochon, Y. and Aebersold, R. (2000) Evaluation of two-dimensional gel electrophoresisbased proteome analysis technology. Proc. Natl. Acad. Sci. USA 97, 9390-9395.

Han, D. K., Eng, J., Zhou, H. and Aebersold R. (2001) Quantitative profiling of differentiation-induced microsomal proteins using isotope-coded affinity tags and mass spectrometry. Nat. Biotechnol. 19, 946-951.

Ho, Y., Gruhler, A., Heilbut, A., Bader, G. D., Moore, L., Adams, S. L., Millar, A., Taylor, P., Bennett, K., Boutilier, K. et al. (2002) Systematic identification of protein complexes in Saccharomyces cerevisiae by mass spectrometry. Nature 415, 180-183.

Houseman, B. T. and Mrksich, M. (2002) Towards quantitative assays with peptide chips: a surface engineering approach. Trends Biotechnol. 20, 279-281.

Huber, C. G., Timperio, A. M. and Zolla, L. (2001) Isoforms of photosystem II antenna proteins in different plant species revealed by liquid chromatography-electrospray ionization mass spectrometry. J. Biol. Chem. 276, 45755-45761.

Jung, E., Heller, M., Sanchez, J. C. and Hochstrasser, D. F. (2000) Proteomics meets cell biology: the establishment of subcellular proteomes. Electrophoresis 21, 3369-3377.

Karas, M. and Hillenkamp, F. (1988) Laser desorption ionization of proteins with molecular masses exceeding 10,000 daltons. Anal. Chem. 60, 2299-2301.

Kawamura, Y. and Uemura, M. (2003) Mass spectrometric approach for identifying putative plasma membrane proteins of Arabidopsis leaves associated with cold acclimation. Plant $J$. 36, 141-154.

Keegstra, K. and Cline, K. (1999) Protein import and routing systems of chloroplasts. Plant Cell 11, 557-570.

Kersten, B., Burkle, L., Kuhn, E. J., Giavalisco, P., Konthur, Z., Lueking, A., Walter, G., Eickhoff, H. and Schneider, U. (2002) Large-scale plant proteomics. Plant Mol. Biol. 48, 133-141.

Koller, A., Washburn, M. P., Lange, B. M., Andon, N. L., Deciu, C., Haynes, P. A., Hays, L., Schieltz, D., Ulaszek, R., Wei, J., Wolters, D. and Yates, J. R. 3rd. (2002) Proteomic survey of metabolic pathways in rice. Proc. Natl. Acad. Sci. USA 99, 11969-11974.

Komatsu, S., Konishi, H., Shen, S. and Yang, G. (2003) Rice proteomics: a step toward functional analysis of the rice genome. Mol. Cell Proteomics 2, 2-10.

Kruft, V., Eubel, H., Jansch, L., Werhahn, W. and Braun, H. P. (2001) Proteomic approach to identify novel mitochondrial proteins in Arabidopsis. Plant Physiol. 127, 1694-1710.

MacBeath, G. (2002) Protein microarrays and proteomics. Nat. Genet. Suppl. 32, 526-532.

Mann, M. and Jensen, O. N. (2003) Proteomic analysis of posttranslational modifications. Nat. Biotechnol. 21, 255-261.

Millar, A. H., Sweetlove, L. J., Giege, P. and Leaver, C. J. (2001) Analysis of the Arabidopsis mitochondrial proteome. Plant Physiol. 127, 1711-1727.

Mitchell, P. (2002) A perspective on protein microarrays. Nat. Biotechnol. 20, 225-229.

Ndimba, B. K., Chivasa, S., Hamilton, J. M., Simon, W. J. and Slabas, A. R. (2003) Proteomic analysis of changes in the extracellular matrix of Arabidopsis cell suspension cultures induced by fungal elicitors. Proteomics 3, 1047-1059.

Pandey, A. and Mann, M. (2000) Proteomics to study genes and genomes. Nature 405, 837-846.

Patterson, S. D. and Aebersold, R. H. (2003) Proteomics: the first decade and beyond. Nat. Genet. Suppl. 33, 311-323.

Peltier, J. B., Friso, G., Kalume, D. E., Roepstorff, P., Nilsson, F., Adamska, I. and van Wijk, K. J. (2000) Proteomics of the chloroplast: systematic identification and targeting analysis of lumenal and peripheral thylakoid proteins. Plant Cell 12, 319342.

Peltier, J. B., Ytterberg, J., Liberles, D. A., Roepstorff, P. and van Wijk, K. J. (2001) Identification of a $350 \mathrm{kDa}$ ClpP protease complex with 10 different Clp isoforms in chloroplasts of Arabidopsis thaliana. J. Biol. Chem. 276, 16318-16327.

Phizicky, E., Bastiaens, P. I., Zhu, H., Snyder, M. and Fields, S. (2003) Protein analysis on a proteomic scale. Nature 422, 208215.

Premstaller, A., Oberacher, H., Walcher, W., Timperio, A.-M., Zolla, L., Chervet, J.-P, Cavusoglu, N., Van Dorsellaer, A. and Huber, C. G. (2001) High-performance liquid chromatographyelectrospray ionization mass spectrometry using monolithic capillary columns for proteomic studies. Anal. Chem. 73, 23902396.

Prime, T., Sherrier, D., Mahon, P., Packman, L. and Dupree, P. (2000) A proteomic analysis of organelles from Arabidopsis thaliana. Electrophoresis 21, 3488-3499.

Rakwal, R. and Agrawal, G. K. (2003) Rice proteomics: current status and future perspectives. Electrophoresis 24, 3378-3389.

Rouquie, D., Peltier, J. B., MarquisMansion, M., Tournaire, C., Doumas, P. and Rossignol, M. (1997) Construction of a directory of tobacco plasma membrane proteins by combined two-dimensional gel electrophoresis and protein sequencing. Electrophoresis 18, 654-660.

Santoni, V., Kieffer, S., Desclaux, D., Masson, F. and Rabilloud, T. (2000) Membrane proteomics: use of additive main effects with multiplicative interaction model to classify plasma membrane proteins according to their solubility and electrophoretic properties. Electrophoresis 21, 3329-3344.

Santoni, V., Rouquie, D., Doumas, P., Mansion, M., Boutry, M., Degand, H., Dupree, P., Packman, L., Sherrier, J., Prime, T., Bauw, G., Posada, E., Rouze, P., Dehais, P., Sahnoun, I., Barlier, I. and Rossignol, M. (1998) Use of a proteome strategy for tagging proteins present at the plasma membrane. Plant $J$. 16, 633-641.

Schweitzer, B., Roberts, S., Grimwade, B., Shao, W., Wang, M., Fu, Q., Shu, Q., Laroche, I., Zhou, Z., Tchernev, V. T., Christiansen, J., Velleca, M. and Kingsmore, S. F. (2002) 
Multiplexed protein profiling on microarrays by rolling-circle amplification. Nat. Biotechnol. 20, 359-365.

Shevchenko, A., Jensen, O. N., Podtelejnikov, A. V., Sagliocco, F., Wilm, M., Vorm, O., Mortensen, P., Shevchenko, A., Boucherie, H. and Mann, M. (1996) Linking genome and proteome by mass spectrometry: large-scale identification of yeast proteins from two dimensional gels. Proc. Natl. Acad. Sci. USA 93, 14440-14445.

van Wijk, K. J. (2001) Challenges and prospects of plant proteomics. Plant Physiol. 126, 501-508.

Vener, A. V., Harms, A., Sussman, M. R. and Vierstra, R. D. (2001) Mass spectrometric resolution of reversible protein phosphorylation in photosynthetic membranes of Arabidopsis thaliana. J. Biol. Chem. 276, 6959-6966.

Washburn, M. P., Wolters, D. and Yates, J. R. 3rd. (2001) Largescale analysis of the yeast proteome by multidimensional protein identification technology. Nat. Biotechnol. 19, 242-247.

Werhahn, W. and Braun, H. P. (2002) Biochemical dissection of the mitochondrial proteome from Arabidopsis thaliana by three-dimensional gel electrophoresis. Electrophoresis 23, 640646.

Werhahn, W., Niemeyer, A., Jansch, L., Kruft, V., Schmitz, U. K. and Braun, H. P. (2001) Purification and characterization of the preprotein translocase of the outer mitochondrial membrane from Arabidopsis. Identification of multiple forms of TOM20. Plant Physiol. 125, 943-954.

Whitelegge, J. P. (2002) Plant proteomics: BLASTing out of a
MudPIT. Proc. Natl. Acad. Sci. USA 99, 11564-11566.

Whitelegge, J. P., Gundersen, C. B. and Faull, K. F. (1998)

Electrospray-ionization mass spectrometry of intact intrinsic membrane proteins. Protein Sci. 7, 1423-1430.

Wilkins, M. R., Pasquali, C., Appel, R. D., Ou, K., Golaz, O., Sanchez, J. C., Yan, J. X., Gooley, A. A., Hughes, G., Humphery-Smith, I., Williams, K. L. and Hochstrasser, D. F. (1996) From proteins to proteomes: large scale protein identification by two-dimensional electrophoresis and amino acid analysis. Biotechnology 14, 61-65.

Wolters, D. A., Washburn, M. P. and Yates, J. R. 3rd. (2001) An automated multidimensional protein identification technology for shotgun proteomics. Anal. Chem. 73, 5683-5690.

Zivy, M. and de Vienne, D. (2000) Proteomics: a link between genomics, genetics and physiology. Plant Mol. Biol. 44, 575580.

Zolla, L., Rinalducci, S., Timperio, A. M. and Huber, C. G. (2002) Proteomics of light-harvesting proteins in different plant species. Analysis and comparison by liquid chromatographyelectrospray ionization mass spectrometry. Photosystem I. Plant Physiol. 130, 1938-1950.

Zolla, L., Timperio, A. M., Walcher, W. and Huber, C. G. (2003) Proteomics of light-harvesting proteins in different plant species. Analysis and comparison by liquid chromatographyelectrospray ionization mass spectrometry. Photosystem II. Plant Physiol. 131, 198-214. 